\title{
EL MECENAZGO EMPRESARIAL COMO EXPRESIÓN DE RECONOCIMIENTO DE RESPONSABILIDAD SOCIAL CORPORATIVA
}

\section{THE CORPORATE SPONSORSHIP RECOGNITION AS AN EXPRESSION OF CORPORATE SOCIAL RESPONSIBILITY}

Luis Felipe Solano Santos: Facultad de Ciencias de la Información de la Universidad Complutense de Madrid. (España)

$\underline{\text { lfsolano@yahoo.es }}$

\section{CURRÍCULUM VITAE}

Doctor en Ciencias de la Información. Licenciado en Periodismo por la Facultad de Ciencias de la Información de la Universidad Complutense de Madrid (España). Es miembro de un Grupo de Investigación Validado Complutense y director de varios proyectos de investigación. Ponente en varios Congresos nacionales e internacionales. Ha publicado tres libros y numerosos artículos en libros y revistas científicas.

\section{RESUMEN}

El presente artículo pretende mostrar el abandono de una concepción ya superada, en la que el mecenazgo se presentaba como manifestación de una actividad filantrópica, para convertirse en expresión de reconocimiento de la responsabilidad social corporativa. La evolución experimentada por el mecenazgo no sólo tiene carácter accesorio, sino que entra en la propia esencia del fenómeno, determinado un 
cambio radical: pasa de ser un ejercicio de libertad y filantropía a ser una acción de responsabilidad en el desarrollo social. Además, se propone que la redefinición del concepto de mecenazgo que debe pasar inexorablemente por la redefinición, a su vez, del concepto de responsabilidad social corporativa, nunca debe estimarse como un acto de liberalidad empresarial, sino como un conjunto de obligaciones.

\title{
PALABRAS CLAVE
}

Mecenazgo - Filantropía - Responsabilidad Social - Imagen

\begin{abstract}
The present article tries to show the abandoning of an already outdated conception, in which patronage appeared as a manifestation of a philanthropic activity, to become an expression of recognition of corporate social responsibility. The evolution experienced by patronage not only has an incidental character, but it enters the very essence of the phenomenon, determining a radical change: it moves from being an exercise of freedom and philanthropy to being a responsible social action. In addition, the article proposes that the redefinition of the concept of patronage that must include inexorably the redefinition of the concept of corporate social responsibility, must never be considered as an act of managerial liberality, but as a set of obligations.
\end{abstract}

\section{KEY WORDS}

Patronage - Philanthropy - Social Responsibility - Image 


\section{ÍNDICE}

\section{Introducción}

2. Evolución histórica del Mecenazgo

3. El Mecenazgo como herramienta de Responsabilidad Social

4. Conclusiones

5. Bibliografía

\section{TEXTO}

\section{Introducción}

A lo largo de la historia se ha considerado el mecenazgo como una actividad altruista o filantrópica, es decir, que nace del amor que los seres humanos profesan a sus semejantes. Sin embargo, el mecenazgo no es eso, sino que es la asunción de una obligación social que sólo unos pocos pueden cumplir. ¿O es qué no estamos todos obligados a proteger el arte y la cultura? Ahora bien, asumir dicha tarea requiere un gran esfuerzo, sobre todo, económico, que los Estados son incapaces de realizar unilateralmente. Por ello, se hace necesaria e imprescindible la participación no sólo de la empresa pública, sino también de la privada, es decir, los entes colectivos formales, aquellas corporaciones que por su volumen y capacidad están en condiciones de liderar el progreso social en todos los órdenes, aquellas organizaciones sobre las que reposa la civilización y garantizan el desenvolvimiento social. A estas organizaciones tanto públicas como privadas, en especial, las multinacionales o también denominas transnacionales debe exigir la sociedad la protección de las artes y la cultura, o sea, la conservación del patrimonio histórico, la promoción artística, la investigación científica y el fomento de la cultura. 
En pocas palabras, el mecenazgo es, sin duda alguna, un instrumento de responsabilidad social corporativa, pues se trata de una obligación derivada del impacto político, económico y medio ambiental que sobre la sociedad tienen las corporaciones.

El presente artículo ofrece el abandono de una concepción afortunadamente ya superada, en la que el mecenazgo se nos presentaba como manifestación de una actividad filantrópica, para convertirse, en expresión de reconocimiento de la responsabilidad social corporativa. La evolución experimentada por el mecenazgo no sólo tiene carácter formal o accesorio, sino que entra en la propia esencia del fenómeno, determinado un cambio radical: pasa de ser un ejercicio de libertad y filantropía a ser una acción de responsabilidad en el desarrollo social.

\section{Evolución histórica del Mecenazgo}

Desde la figura de Cayo Cilnio Mecenas, ciudadano romano del S. I a. de J.C. que da nombre al mecenazgo, hasta nuestros días, muchos han sido los que han dedicado esfuerzos de toda índole, fundamentalmente económicos, a apoyar artistas, fomentar el arte y la cultura, construir y restaurar monumentos, colaborar en investigaciones científicas y descubrir nuevos territorios. Lo que inició Mecenas, uno de los próceres de la época y confidente del emperador romano Octavio Augusto, al apoyar a escritores de la talla de Horacio y Virgilio, se ha convertido con el paso de los siglos en una más que práctica habitual del mundo empresarial. A Mecenas le siguieron muchos otros como el emperador español Trajano, el rey Alfonso X el Sabio, Lorenzo de Médici el Magnífico, el Borgia Alejandro VI, los Reyes Católicos, Felipe II el Prudente, Rockefeller, Juan March, Ramón Areces, y ahora toda organización con o sin ánimo de lucro tanto pública como privada que se precie. Gracias al mecenazgo hoy en día la humanidad disfruta de obras como las del gran Miguel Ángel, se 
beneficia de los tremendos avances tecnológicos y científicos logrados a través de la inversión empresarial y cuenta con el apoyo económico de las organizaciones a la hora de restaurar un monumento o celebrar un evento de magnitud excepcional como es la Exposición Universal o el V Centenario del Descubrimiento de América.

Aunque en un principio esta iniciativa fue considerada como filantropía o altruismo, ahora se entiende como una obligación ineludible y exigible a las corporaciones de todo el mundo. Pues estas corporaciones han superado todas las expectativas, de ser una mera anécdota a lo largo de la historia se han convertido en las principales protagonistas del devenir humano. No en vano, gobiernan países y adoptan decisiones que afectan de forma directa a las sociedades de todo el mundo $y$, por ende, a la vida de los ciudadanos.

Las empresas, son entes culturales, creados única y exclusivamente para servir al ser humano, haciendo su vida mejor y más confortable, facilitando su existencia, y en el cumplimiento de esta finalidad agotan su razón de ser; de ahí, la aberración que suponen aquellas teorías políticas que consideran que el individuo está al servicio del Estado. Podrían traerse a colación otros argumentos como, por ejemplo, la ineludible conexión de los entes culturales con los valores que, como sin duda no ignora el lector, no son, pero "valen" y únicamente puede predicarse este valer en función de su incorporación a hechos o cosas naturales, incorporación que realiza el hombre y que sólo para el hombre tiene virtualidad existencial o axiológica. La empresa, que ha nacido y se desenvuelve en la sociedad, se haya al servicio de ésta, pero, al igual que el ser humano individual, debe colaborar en el mantenimiento del organismo del que recibe la savia nutricia y sin la cual no podría sobrevivir. Naturalmente, la deuda del ser humano con la colectividad es inconmensurable; desde el mismo momento de su nacimiento e incluso antes de él, la sociedad lo acoge, lo alimenta, lo protege, lo educa $y$, teniendo en cuenta que la especie humana, a diferencia de las animales, 
tarda mucho tiempo en alcanzar un desarrollo que le permita valerse por sí mismo, su débito alcanza proporciones extraordinarias. Pero, ¿qué ocurre con las personas jurídicas, con la empresa en este caso? Podría objetarse que las organizaciones satisfacen su deuda con la sociedad pagando sus impuestos; ahora bien, ¿es esto suficiente? El ser humano también paga sus impuestos y además, se ve obligado a satisfacer prestaciones personales, algunas de las cuales son tremendamente onerosas -el servicio militar, por ejemplo, cuya duración llegó a alcanzar varios años- e incluso a poner la totalidad de su persona y bienes a disposición de la sociedad. ¿Cuáles son las prestaciones personales de las empresas?

Una de las cuestiones más problemáticas que se suscitan al tratar el tema de la responsabilidad social del ciudadano corporativo es la referente a la imagen que crea en el lector o estudioso. Todo el que se acerca al mismo concluye por considerar que, en el fondo, se trata de una estratagema más de las empresas para lograr mayores beneficios o, en el peor de los casos, conseguir la supervivencia en un mundo que se les está manifestando hostil. Esta postura se observa incluso en los tratadistas de buena fe que acceden a estas cuestiones.

\section{El Mecenazgo como herramienta de Responsabilidad Social}

Si tuviéramos que establecer un precedente del reconocimiento de la responsabilidad social corporativa, muy pocos dudarían en señalar el mecenazgo como la primera manifestación del mismo; íntimamente unido a la filantropía, la institución es, aunque tímidamente expresada, una realización que traduce una clara conciencia social de que el mundo de los negocios está en deuda permanente con la sociedad que lo acoge y que, en definitiva, es la que hace posible su existencia y desarrollo. 
Ahora bien, el mecenazgo encapsula un riesgo muy grave, riesgo que todavía arrastramos y mucho nos tememos continuaremos arrastrando durante mucho tiempo; resulta curioso, por otra parte, que acciones empresariales que forman parte de lo que se ha calificado con entera justicia de filantropía empresarial, es decir, expresión o manifestación de un talante generoso hacia la sociedad, sean al propio tiempo uno de los mayores obstáculos con que ha tropezado hasta el presente la responsabilidad social corporativa.

El mecenazgo es una acción filantrópica y en consecuencia, totalmente voluntaria, por virtud de la cual la empresa devuelve a la sociedad parte -pequeña- de sus beneficios y se trata, repetimos, de una actividad absolutamente voluntaria; el hecho de que en algunos países sea posible desgravar fiscalmente su coste, ni añade ni quita valor a las mismas -al menos, presumamos la buena fe-, entre otras razones, porque primero fue el hecho y después la consecuencia y nos referimos al dato fiscal. Prescindiendo de que, en numerosas ocasiones, se trata de verdaderas inversiones inversiones en imagen social, en desgravaciones fiscales, en posicionamiento político, etc.-, e incluso presumiendo la buena fe en sus autores, el mecenazgo ha creado la falsa conciencia de hacerlos depender del libre arbitrio de sus autores, lo que ha retrasado hasta la fecha su consideración de actividades exigibles por parte de la sociedad. Pero, aun hay más; en el mecenazgo, la empresa que lo ejerce elige caprichosamente todas y cada una de las circunstancias que lo rodean, que o bien puede ser la reconstrucción de un monumento, la erección de un orfanato, la creación de becas o de premios a la investigación y un larguísimo etcétera, inacabable como inacabable es el universo de las acciones humanas.

Conviene tener presente que, en algunas ocasiones, las actividades de mecenazgo se corresponden con las inquietudes personales de la cúpula directiva de la organización o dicho de otro modo, con las personas que tienen la capacidad de 
decisión, y hemos dicho "inquietudes", por no decir caprichos o aficiones. Sin embargo y a pesar de ello, también en estos casos es la sociedad la principal beneficiaria.

\section{Conclusiones}

¿Y qué es el Mecenazgo? Pues algo tan sencillo como adecuar sus contenidos a las necesidades y requerimientos sociales y una vez hecho esto, conectarlo con la norma de cultura de la sociedad; se trata, en definitiva, de conocer lo que quiere la comunidad y después, conectarlo con su impacto psicológico y con los fines de la organización.

De todo lo dicho se desprende como corolario que el Mecenazgo debe realizarse tras estudios muy detallados y rigurosos acerca de las actitudes de los "públicos" específicos de la empresa y obviamente, en conexión psicológica con el producto, que no deben obedecer al capricho, gustos o aficiones de los directivos y que debe tenerse en cuenta que se trata de un instrumento de comunicación susceptible de afectar a la imagen de la organización.

Recordemos que el Mecenazgo es la protección dada a las artes y la cultura. Y que el concepto originario del mecenazgo responde a la vocación de la empresa de revertir a la sociedad parte de los beneficios que obtiene de ésta, en forma de dividendo social, puesto que es justamente la sociedad quien garantiza su propia existencia.

En consecuencia, se desprende que la redefinición del concepto de mecenazgo debe pasar inexorablemente por la redefinición, a su vez, del concepto de responsabilidad social corporativa, que como hemos repetido hasta la saciedad, nunca y repetimos una vez más, nunca debe estimarse como un acto de liberalidad empresarial, sino 
como un conjunto de obligaciones; y desde luego, tampoco debe considerarse como una técnica, más o menos difícil, más o menos efectiva, de obtener una ventaja competitiva sostenible a largo plazo, o como un instrumento de autodefensa frente a circunstancias sociales adversas.

Esperemos que cuando las aguas vuelvan a su cauce o descubran su curso natural, que es fatal e inexorable, la empresa asuma la responsabilidad social que le corresponde, comenzando por encargar su ejecución a los profesionales a quienes compete y no a advenedizos tecnócratas encapsulados en un economicismo ciego y petulante.

Como colorarlo recordar que lo que un principio se estimó como altruismo o manifestación de actividad filantrópica, concepción afortunadamente ya superada, se presenta ahora como expresión de reconocimiento de responsabilidad social corporativa. Se trata de un cambio radical experimentado a lo largo de la historia a causa principalmente de la evolución social, empresarial y política y por la que se exige al empresariado la asunción de una serie de obligaciones con la finalidad de atender necesidades sociales y que, por supuesto, reportan una alta rentabilidad en imagen. Pues es indudable, como se ha argumentado en anteriores artículos, que la imagen pública es consecuencia directa del grado de asunción de responsabilidad que expresa con su conducta una organización. Y que este comportamiento no es otro, sino el correspondiente al comportamiento esperado. Dicha afirmación coincide con el propio fundamento de las Relaciones Públicas, es decir, la aceptación social está en función del comportamiento de esta naturaleza. 


\section{Bibliografía}

CABRA DE LUNA, Miguel Ángel: "El tercer sector y las Fundaciones en España hacia el nuevo milenio. Enfoque económico, social y jurídico". Madrid, 1998

CUESTA, Marta de la y GALINDO, Angel (Coords.): “Inversiones socialmente responsables". 2005

CUESTA, Marta de la y RODRÍGUEZ DUPLÁ, Leonardo (coords.): “Responsabilidad Social Corporativa". 2004

CUESTA, Marta de la, VALOR MARTÍNEZ, Mamen y SANMARTÍN SERRANO, Sergio: "Inversiones éticas en empresas socialmente responsables". 2002

FERNÁNDEZ DAZA, Eliseo: “Estudio y análisis de los aspectos económicos, financieros y de control de las Fundaciones". Madrid, 1995

FUNDACIÓN EMPRESA Y SOCIEDAD: “La estrategia social de la empresa. En enfoque de valor". Madrid, 1997

FUNDACIÓN EMPRESA Y SOCIEDAD: “Casos de empresas que apoyan el empleo de personas desfavorecidas". Madrid, 1999

FUNDACIÓN EMPRESA Y SOCIEDAD: “De la transparencia a la confianza”. 2003

G. PERDIGUERO, Tomás: “La responsabilidad social de las empresas en un mundo global". 2003 
GIMENO ULLASTRES, Juan Antonio: “Sector público y patrocinio". 1995

JUAN DE ANDRÉS, Amado: "Menenazgo y Patrocinio, las claves del Marketing". Madrid, 1993

MARTÍN FERNÁNDEZ, Javier: "Régimen tributario del mecenazgo en España". Madrid, 1996

MARTÍNEZ, Juan Luis; SIMÓN, Cristina y AGÜERO, Ana: “La acción social de la empresa". 2003

MAYOR ZARAGOZA, Federico: "El papel de las Fundaciones en el desarrollo de la sociedad civil". Santander, 1993

MINGUELLA RUBIO, Francesca: “Menenazgo empresarial: de pasiones y de intereses". Madrid, 1995

MINGUELLA, Francesca; AGUILÁ, Oriol y RABANAL, Marc: “El patrocinio y mecenazgo de empresa en su contexto". Aedme. Madrid, 2000

MINISTERIO DE CULTURA: "El patrocinio empresarial de la cultura en España". Madrid, 1992

MONTOSO CHINER, María Jesús: "Patrocinio Privado y público en el renacer del Gran Teatro del Liceo", Barcelona, 1997

PARES I MAICAS, Manuel: "La Nueva Filantropía y la comunicación social". Barcelona, 1991 
RODRÍGUEZ FERNÁNDEZ, José Miguel: “El gobierno de la empresa. Un enfoque alternativo".

RODRÍGUEZ, Delfín (et al.): “Mecenazgo y conservación del patrimonio artístico: reflexiones sobre el caso español". Madrid, 1995

VICENTE DOMINGO, Elena: “El contrato de Esponsorización” Madrid, 1998

VIDAL PORTABALES, José Ignacio: “El contrato de patrocinio publicitario en el Derecho español". Madrid. 